\title{
IT investments and product development effectiveness: Iranian SBs
}

\begin{abstract}
Purpose: The purpose of this paper is to examine if, and how, investments in IT at different levels can create new product development (NPD) capabilities in terms of IT leveraging competence in NPD and NPD effectiveness. The paper also investigates how Iranian small businesses (SBs) can achieve desired marketing performance through developing these capabilities. Design/methodology/approach: The paper is consistent with the perspective on IT-enabled organizational capabilities. A questionnaire-based survey was conducted to collect data from 218 businesses or NPD managers of SBs in Iran. Findings: IT leveraging competence in NPD and NPD effectiveness are valuable key capabilities that transform the value of IT resources to a firm's performance for Iranian SBs. Investments in both technical and human IT resources have positive effects on the development of NPD capabilities, and thus performance in the surveyed SBs. Research limitations/implications: Among other limitations, relying on a small sample size and cross-sectional data of this research, and lack of generalizability of findings tend to have certain limitations. Practical implications: The results suggest that the investments in both technical and human IT resources increase firms' ability to develop effectiveness in NPD. However, IT investments strategy should be aligned with effective use of IT functionalities, as the effect of IT leveraging competence in development of NPD effectiveness is more pronounced. Second, IT leveraging competence in NPD and NPD effectiveness are important intermediate organizational capabilities through which the benefits of both technical and human IT resources are converted into performance effects at the firm level for Iranian SBs. Originality/value: This case study explores how Iranian SBs can develop NPD capabilities, and subsequently, marketing performance, a topic that has received little attention to date.
\end{abstract}

Keyword: Developing countries; Firm performance; Information technology; Iran; Product development; New product development; Small businesses 